\title{
Constrained Optimization Problems In Cost And Managerial Accounting - Spreadsheet Tools
}

\author{
Thomas T. Amlie, Pennsylvania State University - Harrisburg, USA
}

\begin{abstract}
A common problem addressed in Managerial and Cost Accounting classes is that of selecting an optimal production mix given scarce resources. That is, if a firm produces a number of different products, and is faced with scarce resources (e.g., limitations on labor, materials, or machine time), what combination of products yields the greatest profit to the firm? Solver, an optimization package included within Microsoft Excel (or Optimizer in Quattro Pro), is an ideal vehicle by which to analyze these problems. In most cost or managerial accounting texts, students are asked to address this type of question when there is only one scarce resource (e.g., "Material X"); such problems can be readily solved "by hand". In the case of two or more scarce resources, students are usually referred to their management science classes and Linear Programming packages such as LINDO for further enlightenment, with the comment that such matters are beyond the scope of an accounting text. The purpose of this paper is to illustrate how the Solver package in Microsoft Excel can be easily used to solve optimization problems in management accounting. Although not as powerful or flexible as stand-alone packages such as LINDO, Solver's presence within a universally available spreadsheet package makes it an extraordinarily powerful teaching tool. Instead of parameters being entered into the optimization problem as constants, they can be expressed as functions of other spreadsheet cells. This interactive structure allows an instructor (or student) to create complex production environments where it can be illustrated how minor changes in one aspect of the production environment can flow through and have a profound impact on optimal production schedules.
\end{abstract}

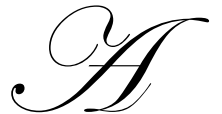

common problem addressed in Managerial and Cost Accounting classes is that of selecting an optimal production mix given scarce resources. That is, if a firm produces a number of different products, and is faced with scarce resources (i.e., limitations on labor, materials, warehouse space, machine time, etc.), what combination of products yields the greatest profit to the firm? Solver, an optimization package included within Microsoft Excel, is an ideal vehicle by which to analyze these problems. Although Solver is not as powerful as stand-alone linear programming packages such as LINDO or MOSEK, its presence within a spreadsheet allows faculty and students to create and work with rich and complex production environments. In addition to the direct curriculum-related (i.e., managerial or cost accounting) benefits which accrue from such exercises, students also are required to increase their facility with spreadsheets as well as their mathematical "model building" skills.

In most cost and managerial accounting textbooks the subject of selecting an optimal production schedule given limitations on resources available will be raised. Usually, problems or exercises in the text are limited to one scarce resource (e.g., "raw material X"), with 2 or more competing uses of that resource. In such a case, the standard solution would be to use the scarce resource in that capacity which provides the greatest contribution (i.e., incremental revenues minus incremental costs) per unit of that scarce resource. This is clearly a simple decision rule, and is appropriately applied in all cases where there is only one scarce resource.

A much more realistic scenario, however, would be one wherein there are multiple scarce or limited resources, each of which has alternative uses. In this case, there is no simple decision rule analogous to the one 
mentioned above. Instead, the decision-maker would need to resort to either a long and tedious hand-generated solution to the problem, or the use of a computer-based linear optimization package. Although some Cost Accounting texts (e.g., Horngren, Datar, and Foster) provide a brief explanation and illustrations of formulating a linear programming problem, none that the author is aware of actually involve using linear programming packages to solve such problems. Most simply leave students with the comment that such issues are beyond the scope of an accounting class. Most students in an Accounting or Business curriculum will be exposed to linear programming as part of a management science class, and using such concepts in an accounting course helps to tie together topics which students are exposed to in various academic disciplines.

\section{Exhibit 1}

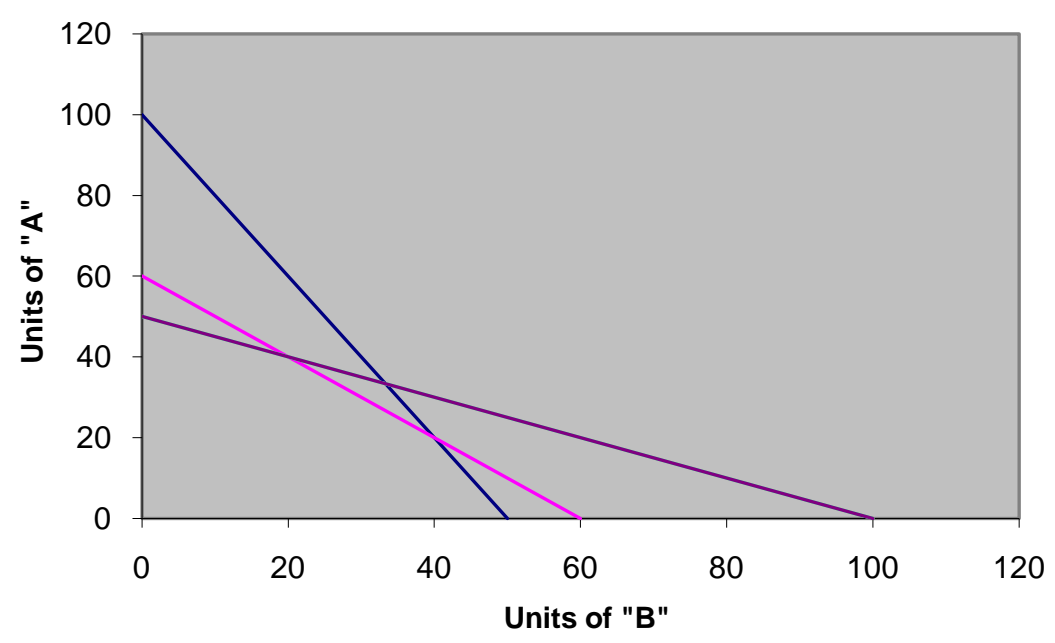

Exhibit 2:

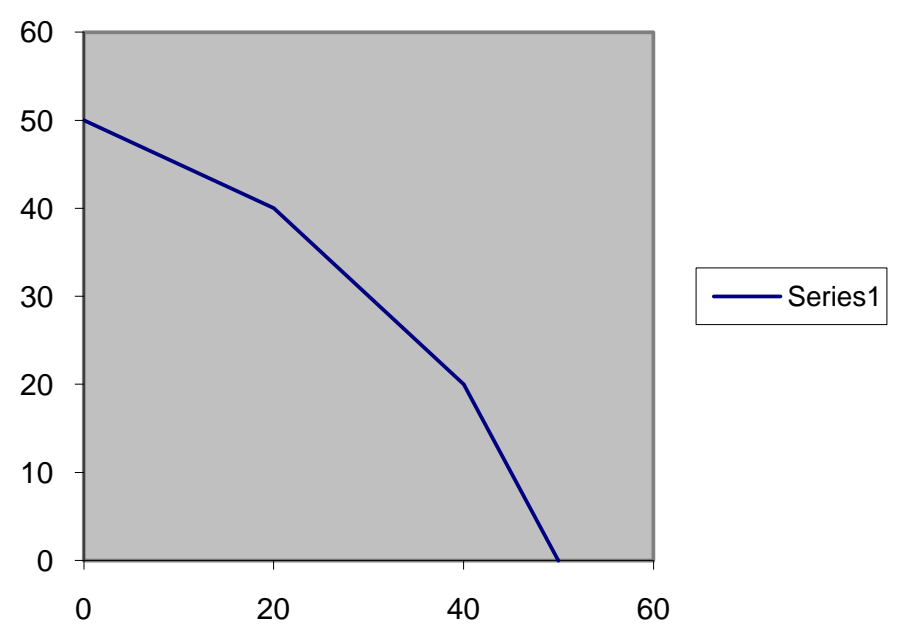

A simple example of such a problem would be as follows:

Assume that a firm produces two products, "A" and "B", which sell for $\$ 110$ and $\$ 46$, respectively. Product "A" uses 4 labor hours, 4 units of materials, and 2 machine hours, while product "B" uses 8 labor hours, 2 units of materials, and 2 machine hours. Also assume that labor costs are $\$ 15$ per hour, while materials cost $\$ 10$ per 
hour, and there are 400 labor hours available, 200 pounds of materials available, and 120 hours of machine time available. Finally, assume that the labor and materials costs are strictly variable, and that there are no other variable or incremental costs associated with the production of products " $\mathrm{A}$ " and " $\mathrm{B}$ ".

Based on the above information, the contribution margins of "A" and "B" are $\$ 10$ and $\$ 6$, respectively. Graphically, the constraints or limitations imposed by our scarce resources would be depicted as in exhibit 1 .

The "steepest" line represents the maximum quantity of "A" and "B" (combined) that can be produced given the limitations on labor, the "flattest" line represents the possibilities given the limitations on materials, and the middle line represents the production possibilities based on the machine time available. Viable production levels are combinations below all three of those lines. After removing the non-feasible line segments the graph of the production possibilities would be as represented in exhibit 2 .

Now let's consider the objective function. As a reminder, the objective function was $\$ 10 \mathrm{~A}+\$ 6 \mathrm{~B}$. Draw in a few "iso-profit" lines (lines on which the total profit is constant). For example, iso-profit lines representing a profits of $\$ 300, \$ 420$, and $\$ 520$ (from left to right) are overlaid on the feasible region in exhibit 3 below:

\section{Exhibit 3}

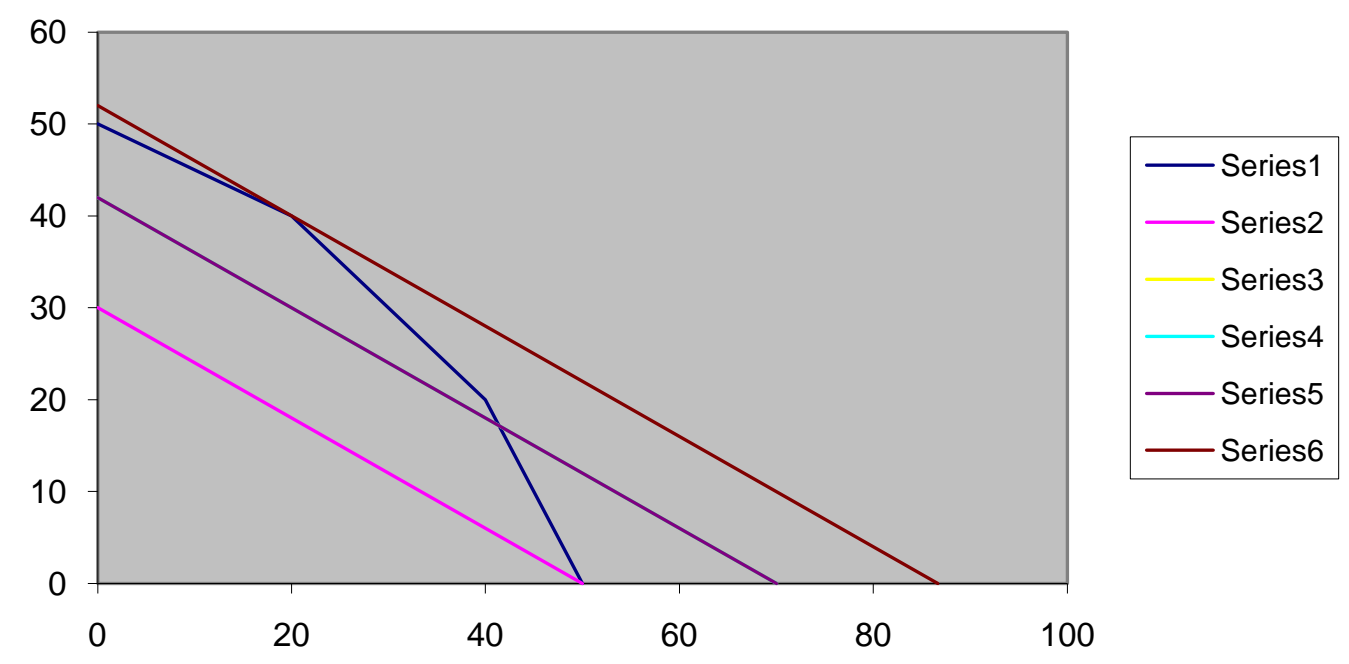

All points on the lowest iso-profit line represent combinations of " $A$ " and "B" which yield a profit of $\$ 300$ (e.g., zero units of "A" and 50 units of "B", or 30 units of "A" and zero units of "B", or other combinations). All points on the highest iso-profit line represent combinations of " $\mathrm{A}$ " and " $\mathrm{B}$ " which yield a profit of $\$ 520$.

Lines further away from the origin represent higher levels of contribution margin. Our goal is to find the highest iso-profit line which still satisfies the constraints. You could view the process as drawing in higher and higher "iso-profit" lines, until any higher-valued line would be outside the feasible region. In this case, the \$520 iso-profit line touches the feasible region at the point representing 40 units of "A" and 20 units of " $\mathrm{B}$ ". If you were to draw in an iso-profit line with a profit of $\$ 521$, it would be completely outside the feasible region.

Please note that the optimal solution resides at a "corner" where 2 or more of the constraints intersected. This will always be the case, unless the slope of the iso-profit line corresponds with the slope of one of the binding constraints. In this case there will be an infinite number of solutions as the iso-profit line and the border of the feasible region will over-lap (e.g., visualize the situation if the slope of the iso-profit line was the same as the slope of one of the line segments defining the feasible region). 
Although a graphical representation (and solution) to such problems is feasible when there are only two competing products, graphical representations become problematical when there are three or more products. When there are three products, the problem requires a three dimensional graph, with the "iso-profit lines" becoming "isoprofit planes". Clearly, a graphical representation is difficult if not impossible, and solving the system of equations by hand is a task that most accounting faculty would not impose upon their students. It therefore becomes necessary to resort to the use of a computer-based linear programming package.

Given that a computerized linear optimization package is called for, there are two basic options: a standalone linear programming package such as LINDO or POM, or a spreadsheet-based optimizer such as Solver in Microsoft Excel or Optimizer in Quattro Pro. The main advantage of LINDO or POM over Solver or Optimizer is the presence in the stand-alone packages of an integer-programming capability. Since many production scenarios involve batch production, the lack of an integer programming capability invariably results in a solution which involves fractional batches. This (hopefully) minor deficiency is more than offset, however, by the flexibility which the spreadsheet packages allow in the specification of the parameters of the problem.

The short problem example illustrated above would be formulated as a linear programming problem in the following manner:

Maximize $10 \mathrm{~A}+6 \mathrm{~B}$ (objective function)

Subject to the following constraints:

$4 \mathrm{~A}+8 \mathrm{~B}<=400$ (Labor constraint)

$4 \mathrm{~A}+2 \mathrm{~B}<=200$ (Materials constraint)

$2 \mathrm{~A}+2 \mathrm{~B}<=120$ (Machine time constraint)

In a conventional linear programming package, the coefficients in the above statements would be entered as constants. If the quantity or price of a resource used by a particular product were to change, the contribution margin (or profit) per unit would have to be separately recalculated and re-entered as a new constant in the objective function, while the "left hand side" of the constraints would require similar manual adjustment.

In a spreadsheet optimization package, the contribution margins in the objective function, as well as the "left hand sides" of the constraints, could be entered as functions of other spreadsheet cells. In other words, the cost and resource use structure of the entire firm could be modeled elsewhere in the spreadsheet, and the optimization problem itself could refer to this "structural model" of the firm. A change in the resource use, or cost of resources, entered into the "model" of the firms activities would automatically be reflected in the objective function and/or constraints in the optimization problem. This aspect is especially useful because students can immediately see how minor changes in the cost or resource use patterns can have profound, and often unexpected, changes in the optimal production levels.

Exhibit 4

\begin{tabular}{|c|c|c|c|}
\hline \multicolumn{2}{|r|}{$\mathrm{B} 2$} & \multicolumn{2}{|c|}{$J x$} \\
\hline 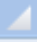 & A & B & $\mathrm{C}$ \\
\hline 1 & & & \\
\hline 2 & Product "A" & & \\
\hline 3 & Product "B" & & \\
\hline 4 & Contribution Mgn & $=10^{*} \mathrm{~B} 2+6^{*} \mathrm{~B} 3$ & \\
\hline 5 & Labor & $=4 * B 2+8 * \Omega 3$ & $=400$ \\
\hline 6 & Materials & $=4 * B 2+2 * B 3$ & $=200$ \\
\hline 7 & Machine hours & $=2^{*} \mathrm{~B} 2+2^{*} \mathrm{~B} 3$ & $=120$ \\
\hline 8 & & & \\
\hline
\end{tabular}




\section{Entering the optimization problem in Excel Solver:}

First, to illustrate the basic functioning of the solver package, consider how the problem illustrated above would be entered if one were to treat the coefficients of the objective function and constraints as constants (see exhibit 4).

Cells "B2" and "B3" are the cells where the "answer" to the problem will appear (i.e., the number of units of "A" and "B"). The objective function and the constraints are entered as functions of these cells. Looking ahead, we can see that great strides in efficiency and flexibility will be obtained if instead of entering the coefficients as constants (e.g., "10", "6", etc.) they are entered as references to other cells where these coefficients are separately computed.

To access the solver module, one would go to the "Data" tab (in Office 2007) and select "Solver". If Solver isn't present in the menu, the "help" function will provide guidance on how to load the Solver module.

Once you select solver, a dialog screen ("solver parameters") will come up. Perform the following steps:

1. The "set target cell" is the cell in which you typed the objective function (total contribution margin in this case; in the above example it is cell "B4");

2. Select whether you wish to maximize or minimize the objective function;

3. "By Changing Cells" is the cell locations of your choice variables; that is, what cells represent the optimal values for "A" and "B" (cells B2 and B3 in the above example). Either use your mouse to highlight the variable cells, or type them in manually. These MUST be the cells referenced in the objective function and constraint equations.

4. Now it's time to enter your constraints; click on "add" and the "add constraint" dialog box will appear. Place the cursor in the "cell reference" box, then click on the cell which contains the left hand side of your first constraint (e.g., "B4"). Next, select whether the correct operator for the constraint is $<$, >, or = (e.g., "<"). Finally, place the cursor in the "constraint" box and click on the right hand side of your constraint (e.g., "C5"). If you wish to add another constraint click "add"; if you are done entering constraints click "OK"

5. Before clicking on "solve" in the "solver parameters" dialog box, be sure to click on options and check the "assume non-negative" box (if applicable). This will ensure that all of your optimal levels of "A" and "B" are non-negative. Alternatively, you could have individual constraints such that " $A$ " is greater than or equal to zero and "B" is greater than or equal to zero.

6. Click on "solve". the optimal values of "A" and "B" should appear in cells B2 and B3 respectively, as will the optimized value of the objective function in cell B4. You should get the following result, as indicated in exhibit 5:

\section{Exhibit 5}

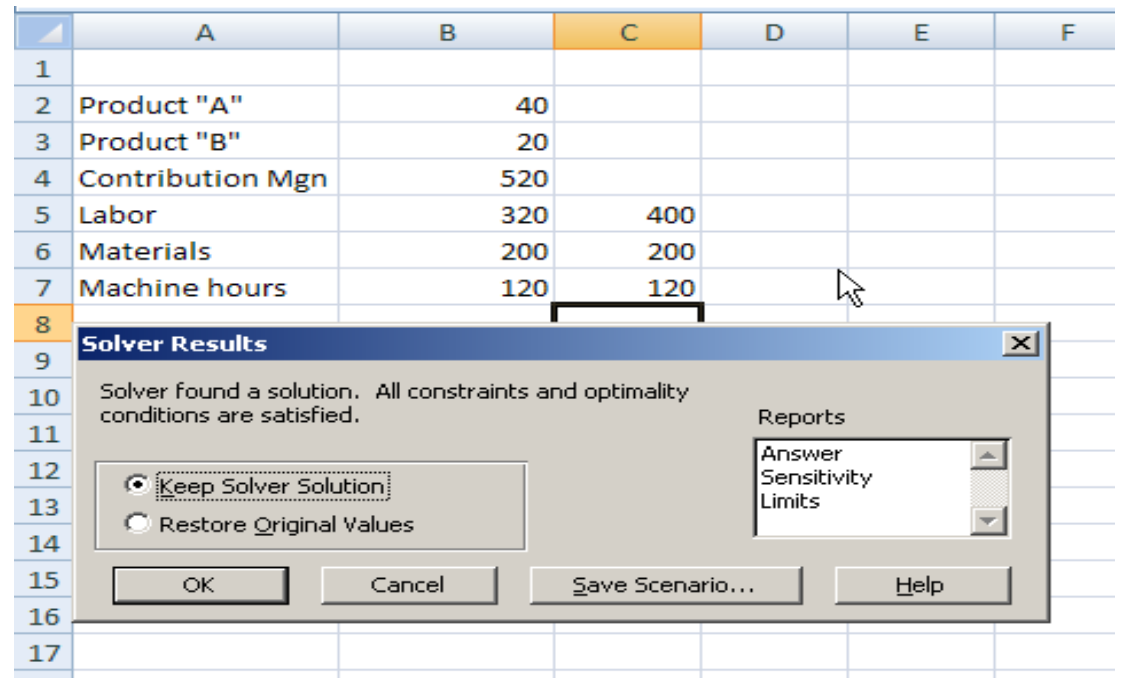


Per this result, the objective function is maximized when 40 units of "A" and 20 units of "B" are produced, at which point the total contribution margin is $\$ 520$.

The values in cells B5, B6, and B7 represent the value of the "left hand side" of each constraint at the optimal solution. For example, the labor (row 5) required that total labor use be less than or equal to 400 units (cell C5); at the optimal solution, 320 labor hours are used (cell B5).

Under the "Reports" box, select all 3 ("Answer", "Sensitivity", and "Limits"), and click on "OK". Three new worksheet tabs should appear; "Answer Report 1", "Sensitivity Report 1", and "Limits Report 1".

Go to the worksheet tab entitled "Answer Report 1" (exhibit 6)

This report indicates:

1. The final value of the objective function (520),

2. The quantities returned for the optimal solution (40 units of "A" and 20 units of "B"), and

3. Whether the individual constraints are binding or not. In this case, the constraints on materials and machine time are binding; that is, they are acting as effective limits on our objective function. The labor constraint is not binding; the "slack" of 80 indicates that the "left hand side" of that constraint is 80 units above (or below) the minimum (or maximum) level allowed. In this case, there are 80 labor hours which are not being utilized.

\section{Exhibit 6}

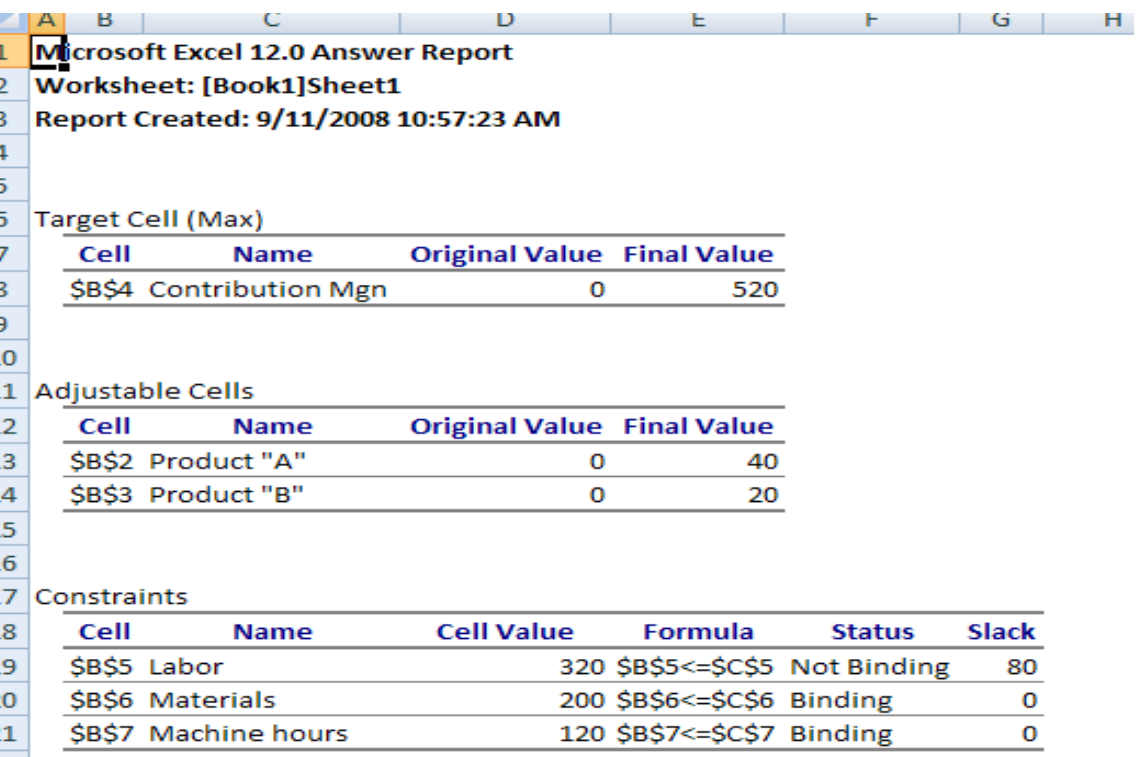

Next, go to the worksheet tab marked "Sensitivity report 1" (exhibit 7). This report provides the LaGrange multipliers or "shadow prices" associated with the various constraints. 
Exhibit 7

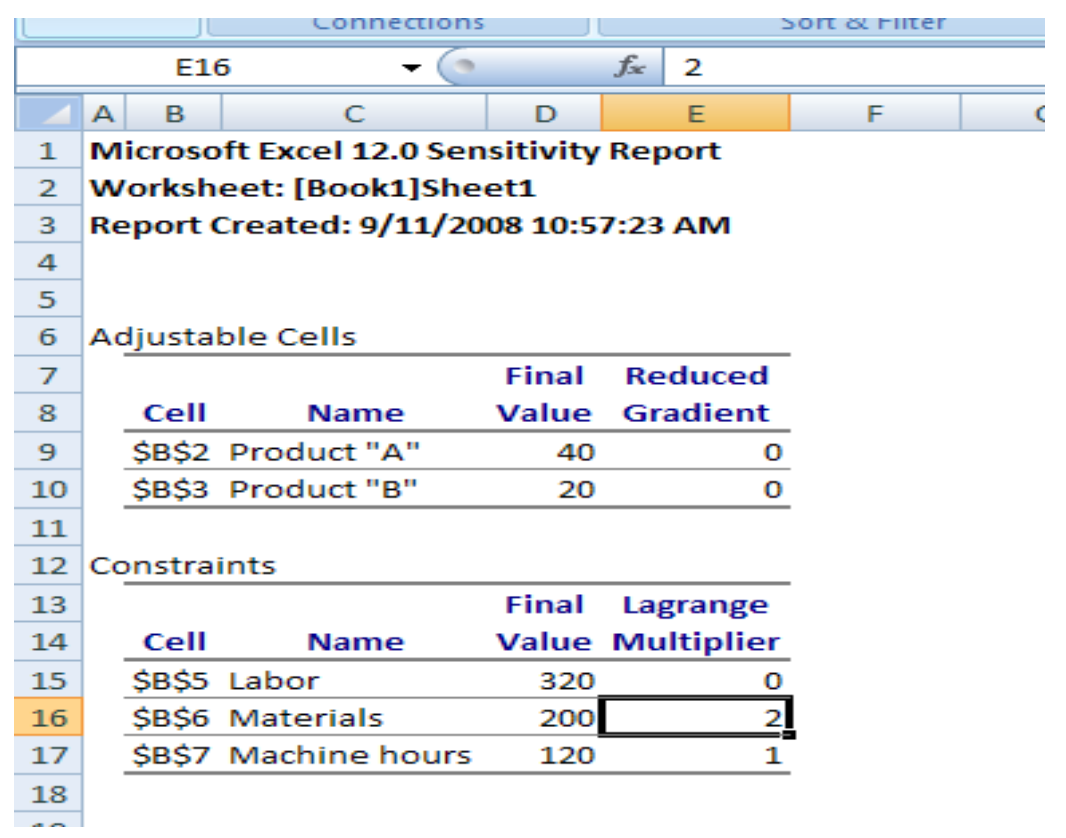

The Lagrange multipliers indicate the value of increasing the right hand side of each constraint by one unit. For example, increasing the right hand side of the materials constraint (the limit on materials available) would increase the objective function by $\$ 2$. In other words, if the quantity of materials available increase to 201 pounds, the objective function would rise to $\$ 522$. The machine time constraint stipulated that a maximum of 120 machine hours were available. If an additional machine hour were to become available, the objective function would increase by $\$ 1$ to $\$ 521$.

Since the labor constraint was not binding, adding additional units of that resource (or "loosening" the constraint by one unit) would not affect the optimal solution.

As was noted at the outset, this is a simple yet inefficient way of formulating an optimization problem in Excel. The contribution margins of "A" and "B" would be functions of the selling price and the variable costs associated with these products. The constraints might be limitations on resources. Both the variable costs and the amounts of resources consumed would properly be functions of the individual characteristics of the two products. A more efficient formulation which would allow "what if" analysis would involve stating resource consumption (and the cost of resources consumed) as a function of the individual product and resource characteristics. In other words, by modeling the cost and resource consumption behaviors of the firm in the spreadsheet, the optimization package can refer back to this model, and changes in the model will be reflected in the solution to the problem. as follows:

As an example, assume a firm manufactures 3 products " $\mathrm{A}$ ", " $\mathrm{B}$ ", and "C". Data for these three products is

\begin{tabular}{|l|c|c|c|c|}
\hline & A & B & C & Cost of resource \\
\hline Selling price/unit & $\$ 33$ & $\$ 38$ & $\$ 50$ & \\
\hline Raw Material "X" & 0.5 & 1.2 & 0.8 & $\$ 8 /$ pound \\
\hline Raw Material "Y" & 1.5 & 1 & 1 & $\$ 2 /$ pound \\
\hline Labor Class I & 1 & 1.2 & 2 & $\$ 12 /$ hour \\
\hline Labor Class II & 0.5 & 0.4 & 0.5 & $\$ 18 /$ hour \\
\hline
\end{tabular}


Assume that there are limits of 10,000 pounds of raw material "X", 8,000 units of Raw material "Y", 8,000 hours of Class I labor, and 16,000 hours of Class II labor. Furthermore, assume that a minimum of 1,000 units of "B" must be produced.

Instead of simply listing the contribution margin of "A" as:

$\$ 33-.5 * \$ 8-1.5 * \$ 2-1 * \$ 12-.5 * \$ 18=\$ 5.00$

it might prove advantageous to set up the spreadsheet to separately compute the resource usage and cost for each product, and have the contribution margin (and constraints) expressed as functions of these cells. For example, exhibit 8 illustrates how the above problem may be entered:

\section{Exhibit 8}

\begin{tabular}{|c|c|c|c|c|c|c|c|}
\hline 4 & A & B & $\mathrm{C}$ & D & E & $\mathrm{F}$ & G \\
\hline 1 & & A & B & C & Cost of resource & Quantity of Res & \\
\hline 2 & Selling price & $\$ 33$ & $\$ 38$ & $\$ 50$ & & & \\
\hline 3 & Raw Material "X" & 0.5 & 1.2 & 0.8 & $\$ 8$ & 10000 & \\
\hline 4 & Raw Material "Y" & 1.5 & 1 & 1 & $\$ 2$ & 8000 & \\
\hline 5 & Labor Class I & 1 & 1.2 & 2 & $\$ 12$ & 8000 & \\
\hline 6 & Labor Class II & 0.5 & 0.4 & 0.5 & $\$ 18$ & 16000 & \\
\hline 7 & $\begin{array}{l}\text { Total Variable } \\
\text { cost }\end{array}$ & 28 & 33.2 & 41.4 & & & \\
\hline 8 & Contribution & 5.00 & 4.80 & 8.60 & & & \\
\hline 9 & Product A & & & & & & \\
\hline 10 & Product B & & & & & & \\
\hline 11 & Product C & & & & & & \\
\hline 12 & Contribution & \multicolumn{2}{|c|}{$=+B 8 * B 9+C 8 * B 10+D 8^{*} B 11$} & & & & \\
\hline 13 & Material X & \multicolumn{2}{|c|}{$=+B \$ 9 * B 3+B \$ 10 * C 3+B \$ 11 * D 3$} & $=+F 3$ & & & \\
\hline 14 & Material Y & \multicolumn{2}{|c|}{$=+B \$ 9 * B 4+B \$ 10^{*} \mathrm{C} 4+\mathrm{B} \$ 11^{*} \mathrm{D} 4$} & $=+F 4$ & & & \\
\hline 15 & Labor I & \multicolumn{2}{|c|}{$=+B \$ 9^{*} B 5+B \$ 10^{*} \mathrm{C} 5+\mathrm{B} \$ 11^{*} \mathrm{D} 5$} & $=+F 5$ & & & \\
\hline 16 & Labor II & \multicolumn{2}{|c|}{$=+B \$ 9^{*} B 6+B \$ 10^{*} \mathrm{C} 6+\mathrm{B} \$ 11^{*} \mathrm{D} 6$} & $=+F 6$ & & & \\
\hline 17 & Minimum "B" & $=+B 10$ & & 1000 & & & \\
\hline
\end{tabular}

By setting up the formulation in this manner it is possible to examine the effect on the optimal solution of a change in resource use (e.g., switching from 0.5 pounds of material X per unit of "A" to 0.55 pounds per unit of "A") or a change in resource costs (e.g., switching the cost of "Labor I" from $\$ 12$ per hour to $\$ 14$ per hour). It becomes a matter of simply changing a parameter and re-running the solver module. Changing any of the entries in cells B2 through F6 will automatically change the values in the objective function, the constraints, row 7 (total variable cost) and row 8 (contribution margin).

Output from the problem as specified is illustrated in exhibit 9 .

The optimal solution involves producing 3,600 units of "A", 1,000 units of "B", and 1,600 units of "C". The constraints on "Material Y" and "Labor I" are binding, as is the constraint that at least 1,000 units of "B" is produced.

Again, this arrangement is convenient as one can readily assess the effects of changes in parameters. For example, if the cost per unit of "Material $\mathrm{Y}$ " were to rise to $\$ 3$ and the selling price of " $\mathrm{A}$ " and " $\mathrm{B}$ " were to rise to $\$ 35$ and $\$ 40$, respectively, the result would be as indicated in exhibit 10 . 
Exhibit 9

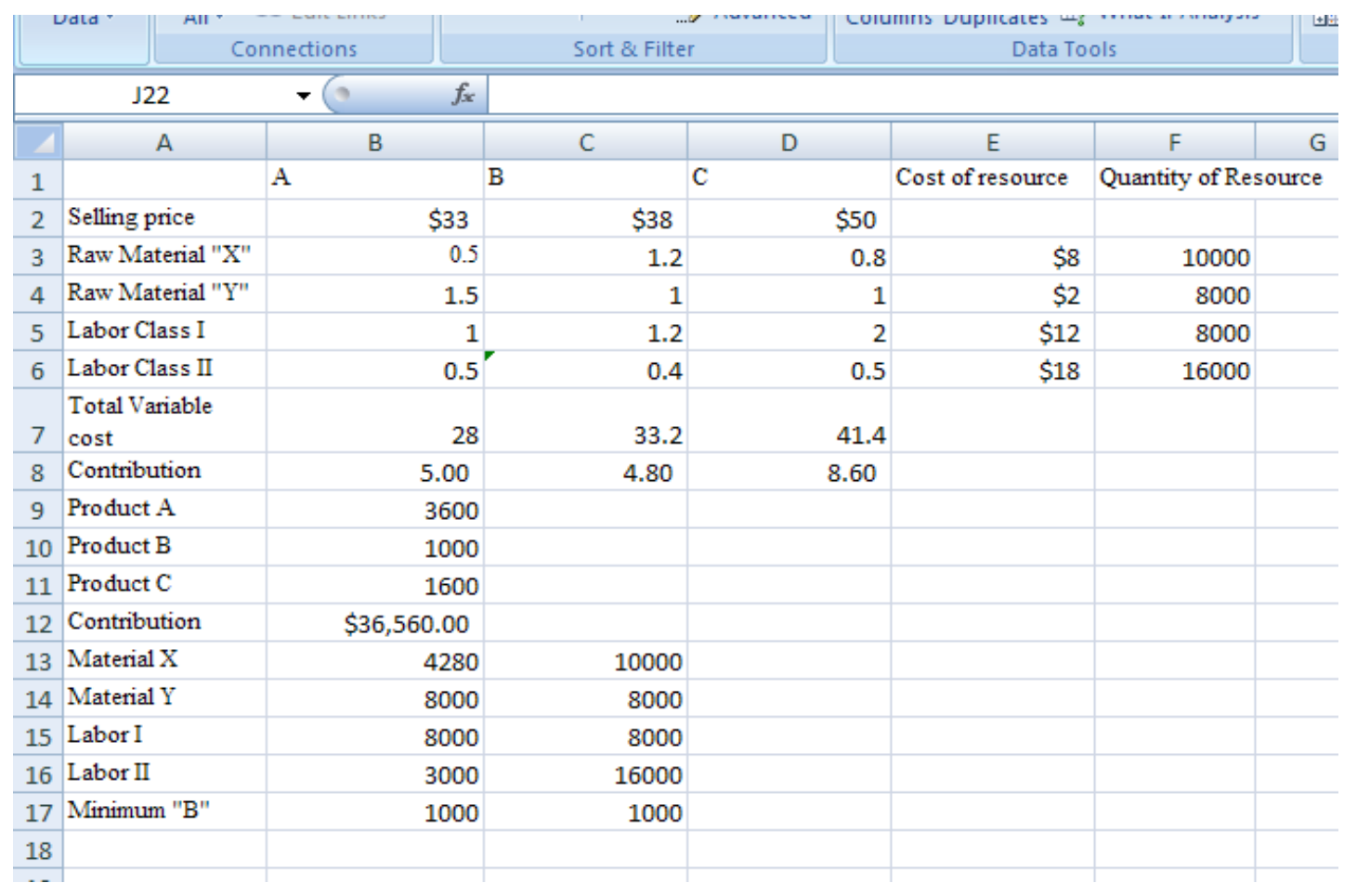

Exhibit 10

\begin{tabular}{|c|c|c|c|c|c|c|c|}
\hline \multicolumn{2}{|r|}{$\mathrm{C} 3$} & $f_{x}$ & \multirow[b]{2}{*}{ C } & \multirow[b]{2}{*}{ D } & \multirow[b]{2}{*}{$\mathrm{E}$} & \multirow[b]{2}{*}{$F$} & \multirow[b]{2}{*}{ G } \\
\hline 4 & A & B & & & & & \\
\hline 1 & & A & B & C & Cost of resource & Quantity of $R e$ & irce \\
\hline 2 & Selling price & $\$ 35$ & $\$ 40$ & $\$ 50$ & & & \\
\hline 3 & Raw Material "X" & 0.5 & 1.2 & 0.8 & $\$ 8$ & 10000 & \\
\hline 4 & Raw Material "Y" & 1.5 & 1 & 1 & $\$ 3$ & 8000 & \\
\hline 5 & Labor Class I & 1 & 1.2 & 2 & $\$ 12$ & 8000 & \\
\hline 6 & Labor Class II & 0.5 & 0.4 & 0.5 & $\$ 18$ & 16000 & \\
\hline 7 & $\begin{array}{l}\text { Total Variable } \\
\text { cost }\end{array}$ & 29.5 & 34.2 & 42.4 & & & \\
\hline 8 & Contribution & 5.50 & 5.80 & 7.60 & & & \\
\hline 9 & Product A & 2000 & & & & & \\
\hline 10 & Product B & 5000 & & & & & \\
\hline 11 & Product C & 0 & & & & & \\
\hline 12 & Contribution & $\$ 40,000.00$ & & & & & \\
\hline 13 & Material X & 7000 & 10000 & & & & \\
\hline 14 & Material Y & 8000 & 8000 & & & & \\
\hline 15 & Labor I & 8000 & 8000 & & گ & & \\
\hline 16 & Labor II & 3000 & 16000 & & & & \\
\hline 17 & Minimum "B" & 5000 & 1000 & & & & \\
\hline 18 & & & & & & & \\
\hline
\end{tabular}

From this solution, one can see that the optimal solution is to produce 2,000 units of "A" and 5,000 units of "B". The "material Y" constraint and the "minimum B" constraints are binding. 
Exhibit 11 presents the "answer report" sheet for the revised formulation; note that there are values for both the "original values" and the "final values". These indicate the changes in the optimal solution due to the changes in the parameters which you made. There is an important caveat which this point raises: the Solver algorithm searches for the optimal solution via a trial and error process, and starts this "search" at whatever the current solution values are. In the above example, Solver would start the search at values of 2,000 for product "A", 5,000 for product "B", and zero for product "C". In more complex problems Solver may provide different "optimal" solutions depending upon the initial values in the problem. As a safeguard against this problem, it is useful to "zero out" the answers before analyzing modified versions of a problem.

\section{Exhibit 11}

\begin{tabular}{|c|c|c|c|c|c|c|c|}
\hline 1 & A B & C & D & E & $\mathbf{F}$ & G & $\mathrm{H}$ \\
\hline 1 & \multicolumn{7}{|c|}{ Microsoft Excel 12.0 Answer Report } \\
\hline 2 & \multicolumn{7}{|c|}{ Worksheet: [test.xlsx]Sheet1 } \\
\hline 3 & \multicolumn{7}{|c|}{ Report Created: 9/11/2008 12:14:31 PM } \\
\hline 4 & & & & & & & \\
\hline 5 & & & & & & & \\
\hline 6 & \multicolumn{7}{|c|}{ Target Cell (Max) } \\
\hline 7 & Cell & Name & Original Value & Final Value & & & \\
\hline 8 & $\$ B \$ 12$ & Contribution A & $\$ 37,760.00$ & $\$ 40,000.00$ & & & \\
\hline 9 & & & & گ & & & \\
\hline 10 & & & & & & & \\
\hline 11 & \multicolumn{7}{|c|}{ Adjustable Cells } \\
\hline 12 & Cell & Name & Original Value & Final Value & & & \\
\hline 13 & $\$ B \$ 9$ & Product A A & 3600 & 2000 & & & \\
\hline 14 & $\$ B \$ 10$ & Product B A & 1000 & 5000 & & & \\
\hline 15 & \$B\$11 & Product C A & 1600 & 0 & & & \\
\hline 16 & & & & & & & \\
\hline 17 & & & & & & & \\
\hline 18 & \multicolumn{7}{|c|}{ Constraints } \\
\hline 19 & Cell & Name & Cell Value & Formula & Status & Slack & \\
\hline 20 & $\$ B \$ 13$ & Material XA & 7000 & $\$ B \$ 13<=\$ C \$ 13$ & Not Binding & 3000 & \\
\hline 21 & \$B\$14 & Material Y A & 8000 & $\$ B \$ 14<=\$ C \$ 14$ & Binding & 0 & \\
\hline 22 & $\$ B \$ 15$ & Labor I A & 8000 & $\$ B \$ 15<=\$ C \$ 15$ & Binding & 0 & \\
\hline 23 & $\$ B \$ 16$ & Labor II A & 3000 & $\$ B \$ 16<=\$ C \$ 16$ & Not Binding & 13000 & \\
\hline 24 & \$B\$17 & Minimum "B" A & 5000 & $\$ B \$ 17>=\$ C \$ 17$ & Not Binding & 4000 & \\
\hline 25 & & & & & & & \\
\hline 144 & $1 \mapsto \cdots<1$ & Limits Report 1 & nswer Report 2 & Sensitivity Repor & rt $2 /$ Limits & oort 2 & \\
\hline
\end{tabular}

Finally, refer to the "sensitivity report" worksheet page (exhibit 12). The "reduced gradient" provides the cost of "forcing" the solution to include one unit of "C". If a constraint were added such that the quantity of "C" must be at least one unit, the optimal value of the objective function would drop by $\$ 1.40$. Similarly, the LaGrange multiplier for the "Material Y" constraint indicates that adding an additional unit of material $\mathrm{Y}$ would cause the objective function to increase by $\$ 1.00$, while increasing the quantity of "Labor I" by one hour would cause the objective function to increase by $\$ 4$.

It should be noted that the information in the "sensitivity report" is valid only for marginal changes from the optimal solution. Increasing the quantity of "Material Y" by 1,000 units does not necessarily mean that the objective function would increase by $1,000 * \$ 2.90=\$ 2,900$.

In addition to providing straight-forward solutions to optimization problems, using Microsoft Excel Solver also allows faculty members to explore or illustrate other concepts in their managerial or cost accounting classes. 


\begin{tabular}{|c|c|c|c|c|c|}
\hline & $1<0$ & Ex & ibit 12 & & \\
\hline 4 & \begin{tabular}{|l|l|}
$A$ & $B$ \\
\end{tabular} & C & D & $E$ & $\mathrm{~F}$ \\
\hline 1 & \multirow{6}{*}{\multicolumn{4}{|c|}{$\begin{array}{l}\text { Microsoft Excel 12.0 Sensitivity Report } \\
\text { Worksheet: [test.xIsx]Sheet1 } \\
\text { Report Created: 9/11/2008 12:14:31 PM }\end{array}$}} & \\
\hline 2 & & & & & \\
\hline 3 & & & & & \\
\hline 4 & & & & & \\
\hline 5 & & & & & \\
\hline 6 & & & & & \\
\hline 7 & & & Final & Reduced & \\
\hline 8 & Cell & Name & Value & Gradient & \\
\hline 9 & $\$ B \$ 9$ & Product A & 2000 & 0 & \\
\hline 10 & \$B\$10 & Product B & 5000 & 0 & \\
\hline 11 & \$B\$11 & Product $\mathrm{C}$ & 0 & -1.399958 & \\
\hline 12 & \multirow{2}{*}{\multicolumn{4}{|c|}{ Constraints }} & \\
\hline 13 & & & & & \\
\hline 14 & & & Final & Lagrange & \\
\hline 15 & Cell & Name & Value & Multiplier & \\
\hline 16 & $\$ B \$ 13$ & Material X & 7000 & 0 & \\
\hline 17 & \$B\$14 & Material Y & 8000 & 1 & \\
\hline 18 & \$B\$15 & Labor I & 8000 & 4 & \\
\hline 19 & \$B\$16 & Labor II & 3000 & 0 & \\
\hline 20 & \$B\$17 & Minimum "B" & 5000 & 0 & \\
\hline
\end{tabular}

Overhead and Activity Based Costing ( $A B C$ ): In a spreadsheet-based optimization package a virtually unlimited number of cost or resource categories can be created. Numerous different cost pools (both fixed and variable) and cost drivers can be utilized to illustrate the importance of the accurate specification and allocation of overhead costs. Again, students should gain additional familiarity with the distinction between the use of resources and the incurrence of additional costs. While each scarce resource (i.e., "activity" in activity based costing) requires a separate constraint, the objective function would only reference those items for which there is an incremental cost. In a non- $\mathrm{ABC}$ environment, it is still possible to illustrate how changes in overhead application rates or bases can have a profound impact on optimal production levels.

Special order questions: In most cost or managerial accounting classes, "special order" questions are often posed; that is, should a special order from a prospective customer be accepted. If posed in the context of a "simple" production environment, such questions are readily addressed without resorting to computer-based models. In a more complex environment, with multiple scarce resources and multiple alternative uses for those resources, a handgenerated solution is difficult to obtain. In a spreadsheet based optimization package, however, students can easily assess the impact of accepting such an order. Students can define a new product (the "special order") with its specific resource consumptions, and add this product to the production environment. By entering a constraint such that the quantity of the "special order" must be at least "one", students can observe the impact on firm profitability of accepting the special order.

Cost behavior patterns: One of the fundamental cost behavior patterns addressed in most cost or managerial accounting courses is the question of whether labor costs are fixed or variable; this "fixed versus variable" question could also be raised in relation to any of a number of other cost categories. Spreadsheet-based optimization packages as illustrated here can reinforce the students' understanding of the distinction between the cost behavior patterns (i.e., that total direct labor costs are fixed) and resource consumption patterns (i.e., that the consumption of direct labor is a linear function of the level of output). In terms of the specific formulation of the linear programming problem, the labor costs would either fall out of the objective function entirely or be treated as a fixed cost, while the variable nature of the resource consumption would still be present in the constraint on labor time. If a faculty member wishes to challenge students' model-building skills they can specify step-cost functions, or add overtime to the labor cost specification. Both of these variations are approachable through judicious use of "if/then" statements.

Changes in resource consumption: As has been noted previously, most Cost and Managerial Accounting textbook examples have only one constraint. In such an example, if the resource consumption of one product increases, the 
quantity of that product produced will fall. In a larger example, with a more realistic number of constraints, such a simplistic assessment is not always correct. Using a spreadsheet-based optimization package such as Solver allows faculty to highlight the importance of the interrelationship between constraints.

As an example, return to the original illustration with products "A", "B", and "C" (exhibit 9). Assume that there is some concern that product " $\mathrm{C}$ " usage of "Material $\mathrm{Y}$ " may be misspecified, and that the actual use per unit may be somewhat higher at 1.2 pounds per unit. A reasonable intuitive expectation would be that if product " $\mathrm{C}$ " were to consume more of "Material Y: the number of units of "C" produced would decrease. However, if we change that parameter in the Solver model (i.e., increase cell D4 from 1 to 1.2) we find that production of product $\mathrm{B}$ increases from 1,600 units to 1,778 units (exhibit 13). As Material Y becomes "more scarce" as a result of the increased consumption by product "C", it becomes more important to maximize the contribution margin per unit of Material Y.

\section{Exhibit 13}

\begin{tabular}{|c|c|c|c|c|c|c|c|}
\hline 4 & A & B & C & D & E & $\mathrm{F}$ & G \\
\hline 1 & & A & B & $\mathrm{C}$ & Cost of resource & Quantity of Res & \\
\hline 2 & Selling price & $\$ 33$ & $\$ 38$ & $\$ 50$ & & & \\
\hline 3 & Raw Material "X" & 0.5 & 1.2 & 0.8 & $\$ 8$ & 10000 & \\
\hline 4 & Raw Material "Y" & 1.5 & 1 & 1.2 & $\$ 2$ & 8000 & \\
\hline 5 & Labor Class I & 1 & 1.2 & 2 & $\$ 12$ & 8000 & \\
\hline 6 & Labor Class II & $0.5^{\prime}$ & 0.4 & 0.5 & $\$ 18$ & 16000 & \\
\hline 7 & $\begin{array}{l}\text { Total Variable } \\
\text { cost }\end{array}$ & 28 & 33.2 & 41.8 & & & \\
\hline 8 & Contribution & 5.00 & 4.80 & 8.20 & & & \\
\hline 9 & Product A & 3244 & & & & & \\
\hline 10 & Product B & 1000 & & & & & \\
\hline 11 & Product C & 1778 & & & & & \\
\hline 12 & Contribution & $\$ 35,600.00$ & & $\zeta$ & & & \\
\hline 13 & Material X & 4244.4444444 & 10000 & & & & \\
\hline 14 & Material Y & 8000 & 8000 & & & & \\
\hline 15 & Labor I & 8000 & 8000 & & & & \\
\hline 16 & Labor II & 2911.111111 & 16000 & & & & \\
\hline 17 & Minimum "B" & 1000 & 1000 & & & & \\
\hline 10 & & & & & & & \\
\hline
\end{tabular}

\section{SUMMARY}

In conclusion, the use of spreadsheet-based optimization packages such as Solver or Optimizer can be of great benefit in teaching topics in managerial and/or cost accounting. The interplay between multiple scarce resources and multiple potential uses of those resources can be modeled, and the profound (and sometimes counterintuitive) effects of seemingly trivial changes in resource use assumptions or assumed cost behavior patterns can be illustrated. Output from these problems can be viewed simply in terms of the value of the objective function obtained, or faculty can require students to set up the spreadsheet so that a "proper" income statement is generated using the output.

The use of these programs has several benefits beyond the specific accounting-curriculum issues noted. It increases the students' facility with spreadsheets and mathematical model building, and provides students with the opportunity to apply management science topics to their accounting course-work.

A "linear programming with solver" tutorial which has been developed for distribution to accounting students can be obtained from the author upon request. 